\title{
Methods of Improving Mechanical Integrity of Center-Link Chains for a Trolley Conveyor System
}

\author{
Changwan Han ${ }^{1} \cdot$ Jae-hoon Lee ${ }^{2} \cdot$ Yoon Suk Choi ${ }^{3} \cdot$ Sang-Hu Park ${ }^{1} \cdot$ Seonghun Park ${ }^{1}$
}

Received: 20 September 2017 / Revised: 30 December 2018 / Accepted: 15 January 2019 / Published online: 13 February 2019

(c) The Author(s) 2019

\begin{abstract}
The purpose of this study is to identify the causes of the continuous failure of center-link chains for a trolley conveyor system by analyzing their failure characteristics under static and dynamic loading conditions and to propose methods for securing their mechanical integrity. For this purpose, center-link chains were minimally processed to prepare testing specimens with their original surface property and structural dimension maintained. These specimens were used to measure the tensile strength (1172.1 MPa), elongation (8.7\%), yield strength (1073.4 MPa), hardness (44.1 HRC), and surface roughness $\left(R_{a}=10.5 \mu \mathrm{m}\right)$. A three-point bending fatigue test $(\mathrm{R}=0.1)$ resulted in a fatigue limit of $746.7 \mathrm{MPa}$. The results confirmed that the rough surface of the center-link chain caused a reduction in the elongation and fatigue limit and an increase in the scattering of the surface hardness and fatigue life, which were the direct causes of frequent chain failure in the field. To improve the fatigue life of the center-link chain, two methods were reviewed in this study. The first method was to reduce its surface roughness through surface machining of the center-link chain, and the second was to modify its shape design to allow improved structural integrity, even if the current surface roughness is retained. In the case of the first method, the results of the fatigue test using the specimen with reduced surface roughness (from $R_{a}=10.5$ to $0.9 \mu \mathrm{m}$ ) by surface machining demonstrated reduced scattering and increased fatigue limit (from 746.7 to $920.3 \mathrm{MPa}$ ). As for the second method, a stiffener was added and two design variables (slope angle and fillet radius) of the stiffener were selected to propose a new design that can reduce the maximum stress $\sim 1.6$ times compared to the conventional design. While both methods for improving the structural integrity of the center-link chain were effective enough to improve the fatigue life of the chain, the second method, which requires only the initial mold manufacturing cost for modifying the shape design of the chain, was finally selected, because it exhibited better economic feasibility than the first method that increases the product cost and overall process time due to addition of the surface machining process.
\end{abstract}

Keywords Center-link chain · Fatigue life $\cdot$ Failure analysis $\cdot$ Surface roughness $\cdot$ Mechanical integrity $\cdot$ Trolley conveyor system

\section{Introduction}

Changwan Han and Jae-hoon Lee contributed equally to this work.

Seonghun Park

paks@pusan.ac.kr

1 School of Mechanical Engineering, Pusan National University, Busan 46241, South Korea

2 Korea Marine Equipment Research Institute, Busan 49111, South Korea

3 School of Materials Science and Engineering, Pusan National University, Busan 46241, South Korea
A trolley conveyor is a device that can transport vehicle bodies along a rail by placing trolleys at regular intervals on the rail installed on the ceiling of the vehicle assembly factory. The center-link chain, a component to connect trolleys in the trolley conveyor, is the key part to deliver driving power to all the trolleys and provide synchronized movement. The rupture of center-link chains has caused frequent interruptions in a series of processes in actual vehicle assembly lines. As the center-link chain is exposed to repeated loading changes, it is vulnerable to fatigue failure. Mostly brittle fracture occurs because it is designed to have high hardness to prevent wear caused by contact between chains [1]. Therefore, the 
unexpected fatigue failure of the chain frequently occurs, and the workers cannot easily recognize such situation [2]; there is a problem of spending as much as $112 \mathrm{~min}$ on average per case for the chain replacement causing the shutdown of the assembly line. As the fatigue failure of the center-link chain results in considerable economical damage, it is very important to accurately predict its fatigue life when it is designed and to prevent its fatigue failure in advance [3-7].

Kim et al. [8] evaluated the structural stability of the chain for ceiling cranes by predicting its deformation behavior and obtaining its maximum allowable load according to its loading type (tension or bending). Liu et al. [9] performed a finite element analysis to analyze the strength of the trolley beam of the crane and reduced its weight by approximately $16 \%$ compared to the existing crane through an optimization of the crane. Kitsunai et al. [10] conducted a fatigue test to investigate the factors affecting the rupture in the gusset plate of the overhead travelling crane, and confirmed that the rupture occurred due to the gradual progression of cracks in the area where high stress was concentrated. As seen by the previous studies cited above, most studies were conducted to predict the behavior of trolley beams or chains for cranes under the loading conditions and evaluate their structural stability. Although they were conducted to secure the safety of transport equipment as in this study, it was difficult to find studies conducted on trolley conveyors. Furthermore, previous studies have evaluated the fatigue life of the target structure based on the test results of standard testing specimens $[11,12]$. Therefore, the fatigue life of the actual product can be significantly shorter than the fatigue life predicted using the standard testing specimens [13-16], because the fatigue life of the actual product is influenced not only by the stress-concentrated shape of the structure, but also by the inhomogeneous material distribution and the surface condition according to the manufacturing process such as heat treatment [17-20]. For example, because the center-link chain of this study is produced by forging the raw material, its mechanical properties and such as surface roughness are affected by the material inhomogeneity of the interior and exterior of the product [21-23]. In addition, as the processes including heat treatment or surface treatment after forging have a considerable effect on the mechanical properties of the product, a significant number of factors affect the initially predicted design values and fatigue life [24, 25]. Therefore, it is necessary to verify the structural stability of the continuously problematic target structure in the actual industrial field considering the influencing factors related to the manufacturing process and to reflect the verification results to the design for the structural reliability [26, 27].

The purpose of this study is to identify the causes of the continuously occurring problem of center-link chains made of SCM440 material, which are used in the vehicle assembly factories, by analyzing their failure characteristics under static and dynamic loading conditions and to propose methods for securing their mechanical integrity through changes in their design or manufacturing processes. For this purpose, the material strength, hardness, surface roughness, and fatigue characteristics of the center-link chain, which affect its static and dynamic failure, were investigated quantitatively and its shape design was modified to allow improved mechanical integrity, even if the surface roughness is considered.

\section{Materials and Methods}

\subsection{Preparation of Specimen}

The subject of this study is the center-link chain made through the forging process and its material is SCM440, which is chromium-molybdenum alloy steel. The chemical composition of SCM440 contains $0.90-1.20 \mathrm{wt} \%$ chromium and $0.15-0.35 \mathrm{wt} \%$ molybdenum (Table 1). It is resistant to corrosion and has excellent mechanical properties, and thus is widely used as alloy steel for mechanical structures.

The surface of the center-link chain that is used in the actual field is very rough and may produce different mechanical properties from the standard specimens, depending on the uneven stress distribution. Therefore, unlike previous studies that use testing specimens without surface defects or internal inhomogeneity, this study used testing specimens minimally machined from the actual product. The testing specimens were prepared in consideration of the highly loaded area of the center-link chain where damage occurs during the operation in the actual field (Fig. 1). As for the testing specimen to be extracted from the center-link chain, the stress distribution occurring under the main acting loads (tensile and bending loads, Fig. 2) on the center-link chain was examined in advance through a finite element analysis to determine the cutting points sufficiently distant from the section with the maximum stress. Then, the testing specimens were prepared by applying minimal machining to the actual center-link chain product and preserving its surface (Fig. 3).

Table 1 Chemical composition (wt \%) of SCM440

\begin{tabular}{ll}
\hline Composition & $\begin{array}{l}\text { Chemical } \\
\text { content } \\
\text { (wt\%) }\end{array}$ \\
\hline $\mathrm{C}$ & $0.38-0.43$ \\
$\mathrm{Si}$ & $0.15-0.35$ \\
$\mathrm{Mn}$ & $0.60-0.85$ \\
$\mathrm{Cr}$ & $0.90-1.20$ \\
$\mathrm{Ni}$ & $<0.25$ \\
$\mathrm{Mo}$ & $0.15-0.35$ \\
$\mathrm{P}$ & $<0.03$ \\
$\mathrm{~S}$ & $<0.03$ \\
\hline
\end{tabular}




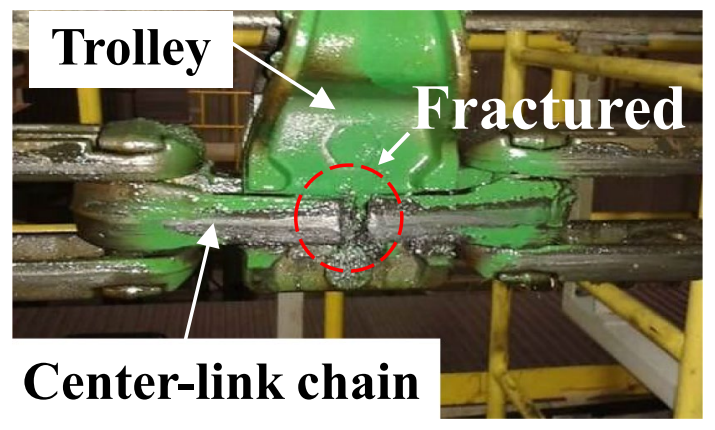

Fig. 1 Fractured area in the middle of the center-link chain

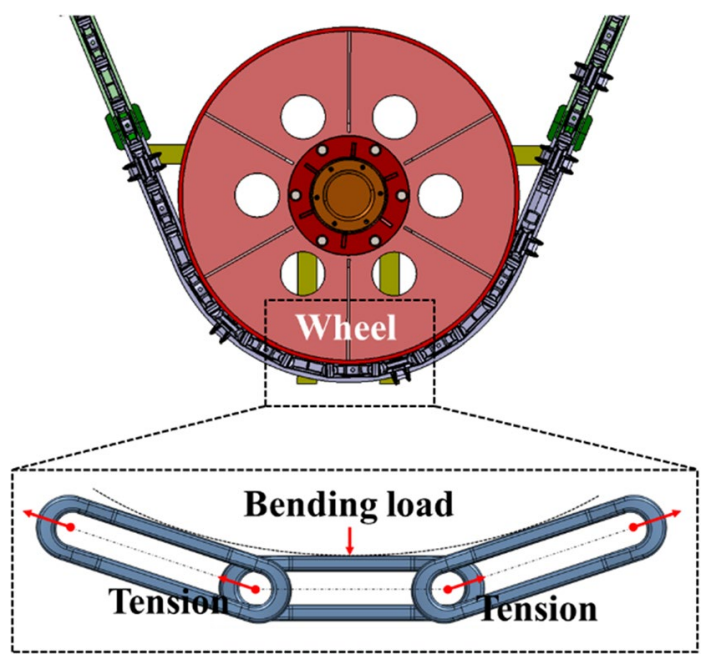

Fig. 2 Loading conditions: tensile and bending loads applied on the center-link chain

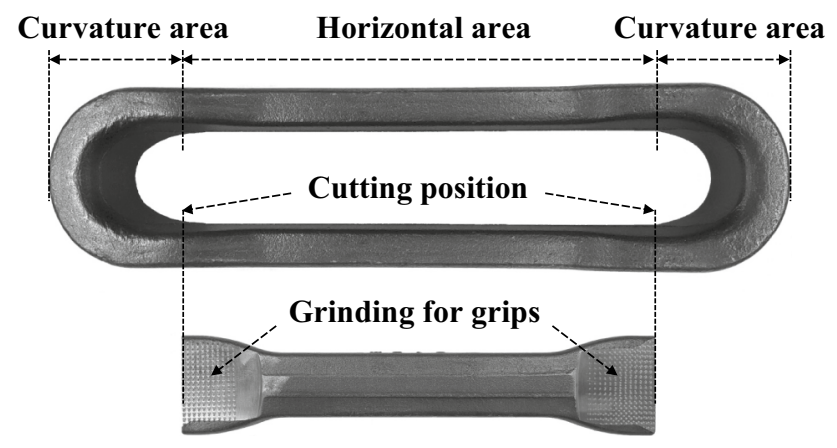

Fig. 3 Testing specimens machined from center-link chain products: center-link chain product and testing specimen manufactured from the center-link chain product by cutting both ends of its horizontal area and grinding those ends for tensile grips

\subsection{Tensile and Hardness Tests}

Tensile tests were conducted to identify the basic mechanical properties of the center-link chain made of SCM440 (a) Tensile testing machine

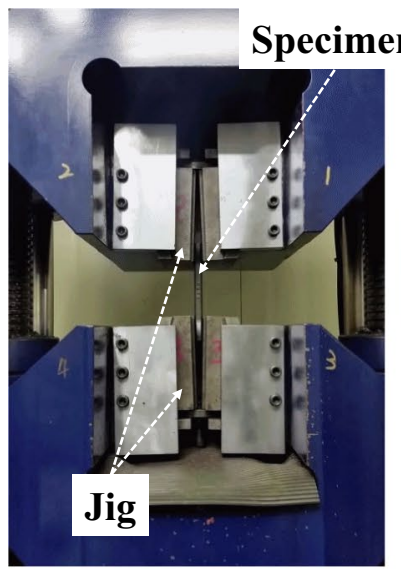

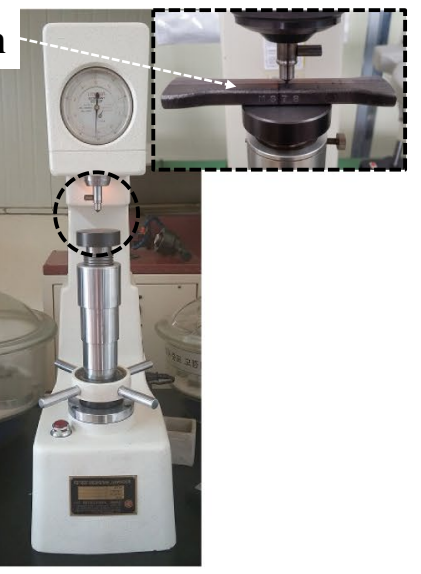

(b) Hardness testing machine

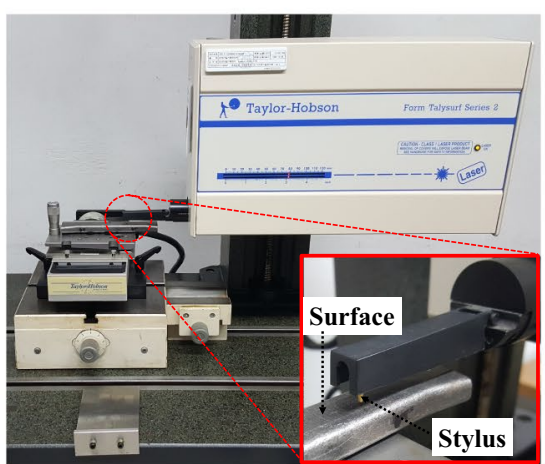

(c) Surface roughness testing machine

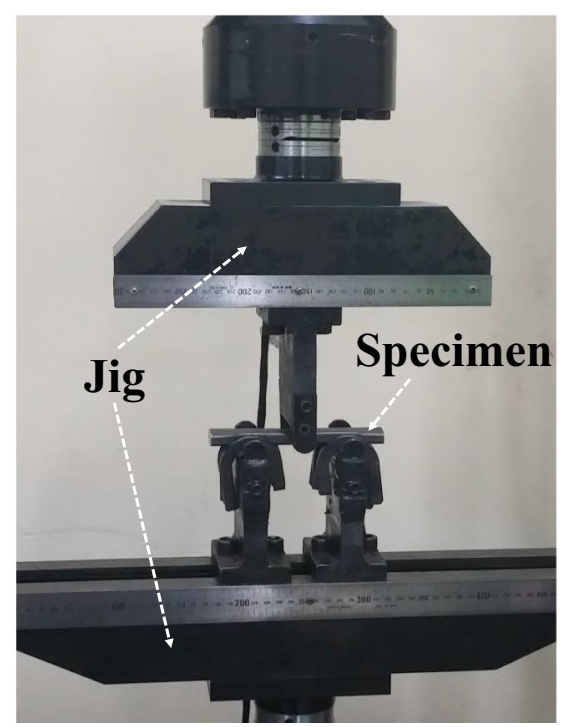

(d) Three-point bending fatigue testing machine

Fig. 4 Testing machines with specimens mounted

material. The tensile tests were conducted at room temperature $\left(25^{\circ} \mathrm{C}\right)$ with a $1 \mathrm{~mm} / \mathrm{min}$ loading speed using testing specimens $(\mathrm{n}=3)$ with a $50 \mathrm{~mm}$ gauge length (Fig. 4a). The 
load was slowly increased until the testing specimens were ruptured. Then, strain was computed from the change in the grip-to-grip length relative to the initial grip-to-grip length. The tensile strength, yield strength, and elongation were then calculated based on the results from the stress-strain diagram. The surface hardness was measured from a total of 60 points of the six testing specimens at $10 \mathrm{~mm}$ intervals using a Rockwell hardness tester (C scale, $150 \mathrm{~kg}_{f}$, Matsuzawa, Japan) (Fig. 4b).

\subsection{Surface Roughness Measurements}

The surface roughness needs to be identified because it is an element that can affect the fatigue life or the strength of a product under general tensile loading conditions. The rough surface of the center-link chain is visible with the naked eyes because and surface machining was not applied on the testing specimens and the surface property of the center-link chain product was preserved. The surface roughness values of the testing specimens were measured using Talysurf Series 2 (Taylor-Hobson Ltd, UK) to obtain quantitative data (Fig. $4 \mathrm{c}$ ). The surface roughness was measured for a total of 15 testing specimens with a $45 \mathrm{~mm}$ gauge length and a speed of $0.25 \mathrm{~mm} / \mathrm{s}$, and the average roughness $\left(R_{a}\right)$ values and the maximum height roughness $\left(R_{\max }\right)$ were obtained.

\subsection{Fatigue Test}

The inside of the center-link chain is fastened to the trolley and it moves along with the trolley. In this instance, the chain is basically subject to tension. When the trolley passes the wheel, a bending load is further applied to the center of the center-link chain in addition to the tension. The bending load in the latter situation is more severe in terms of stress distribution of the center-link chain. Therefore, a three-point bending fatigue test was conducted to fully reflect the latter condition (Fig. 4d).

For the fatigue test, an MTS 810 (MTS Systems Corporation, US), a hydraulic dynamic material testing machine with a maximum capacity of 10 tons, was used. Both the supporting part and loading part of the specimen holding jig were made in the same semicircular shape $(\mathrm{r}=15 \mathrm{~mm})$, and mirror surface machining was applied to its surface to minimize friction due to its contact with the testing specimens during testing. When the three-point bending fatigue test was conducted, the specimens were placed in the center of the supporting point so that they could not be deflected to the left or right, and the bending stress was generated by applying a load at half the distance between the supporting points. For the fatigue loading conditions, the repetition frequency was set to a $5 \mathrm{~Hz}$ sinusoidal profile and the stress ratio was 0.1 . The fatigue test was performed until the specimens were completely ruptured. The fatigue life to determine the fatigue limit was set to $1 \times 10^{6}$ cycles and more cycles were set as run-out to obtain the $\mathrm{S}-\mathrm{N}$ curve.

\section{Results and Discussion}

\subsection{Tensile and Hardness Test}

The load-displacement curves of the testing specimens with rough surfaces preserved from the center-link chain product were obtained from the tensile test, and then converted to the engineering stress-strain curves (Fig. 5). As a result, the tensile strength was found to be $1175.9 \pm 17.8 \mathrm{MPa}$ $(n=3)$, the yield strength obtained through the $0.2 \%$ offset method was $1065.3 \pm 23.3 \mathrm{MPa}(\mathrm{n}=3)$, and the elongation was $8.7 \pm 0.5 \%(n=3)$. In addition, the surface hardness measured using the Rockwell hardness tester was $44.1 \pm 3.1$ HRC $(n=60)$. It is believed that the hardness value varied depending on the position because the surface of the subject of this study was very rough.

Among the above results, the tensile strength and the yield strength satisfied the standard values set forth in JIS G4105-1979, but the elongation was approximately $40 \%$ lower. It is believed that the elongation was lower than the standard value because the very rough surface condition led to the notch effect and caused the rapid fracture of the testing specimens.

\subsection{Surface Roughness Measurements}

Before conducting the fatigue test, the surface roughness was measured for a total of 15 testing specimens. As a result, the average roughness $\left(R_{a}\right)$ was $10.5 \pm 1.7 \mu \mathrm{m}$ $(\mathrm{n}=15)$ and the maximum height roughness $\left(R_{\max }\right)$ was $87.9 \pm 16.2 \mu \mathrm{m}(\mathrm{n}=15)$. It was quantitatively confirmed

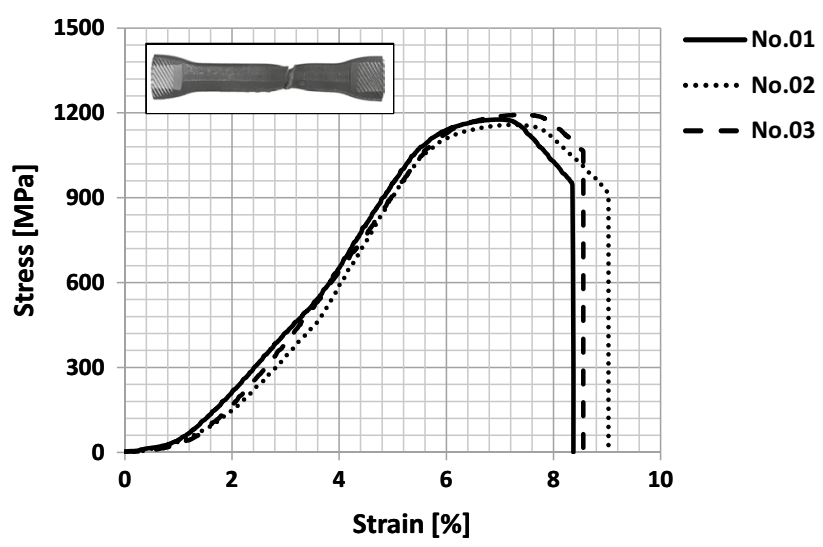

Fig. 5 Engineering stress-strain curves from tensile tests 
that the surface of the center-link chain product was very rough owing to the nature of the forging process applied to the product.

\subsection{Fatigue Test}

After conducting the fatigue test, the $\mathrm{S}-\mathrm{N}$ (stress-fatigue life) curve was obtained (Fig. 6). The S-N curve showed linear behavior on a log scale and fitted with a linear equation. Then, this equation on a linear scale becomes:

$S_{\max }=2047.2 \times N_{f}^{-0.073}$

where $S_{\max }$ is the maximum stress applied to the specimen and $N_{f}$ is the corresponding fatigue life.

The fatigue limit calculated at $1 \times 10^{6}$ cycles from Eq. (1) was 746.7 MPa. The coefficient of determination $\left(R^{2}\right)$ measured as $R^{2}=0.751(\mathrm{n}=15)$. This $R^{2}$ value is a statistical value and a value closer to 1 indicates that the data are closer to the linear trend line. Therefore, it was found that there was a significant scattering in the fatigue life of the testing specimens due to the high surface roughness of the center-link chain. In particular, the results of the fatigue test in the high-cycle region revealed that the fatigue life was 118,949 cycles at a stress of $827 \mathrm{MPa}$, 289,741 cycles at $810 \mathrm{MPa}$, and $1,000,000$ cycles at $800 \mathrm{MPa}$ (Fig. 6). In other words, a fatigue life difference of approximately 9 times $(=1,000,000 / 118,949)$ occurred among the testing specimens at stress levels close to $800 \mathrm{MPa}$. This scattering result due to the high surface roughness confirmed that there could be a difficulty in

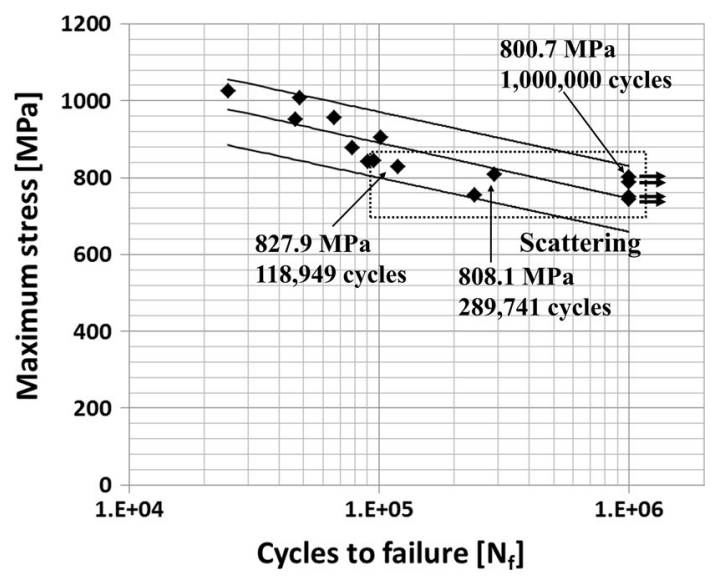

Fig. 6 Fatigue test results of testing specimens without surface machining $(n=15)$ that are presented with the upper and lower limits of a $95 \%$ confidence level. The fatigue life was 118,949 cycles at a stress of $827 \mathrm{MPa}, 289,741$ cycles at $810 \mathrm{MPa}$, and 1,000,000 cycles at $800 \mathrm{MPa}$, revealing a significant scattering in the fatigue life securing the reliability of the fatigue life of the centerlink chain.

\subsection{Fatigue Life Improvement Methods of the Center-Link Chain}

To improve the fatigue life of the center-link chain of this study, the method of reducing the surface roughness through the surface machining process was examined first, and then the method of modifying the design to allow improved structural integrity, even when the current surface roughness is retained, was examined as an alternative. It was judged effective to select a method of the two that is more appropriate in terms of economic efficiency to be applied to the product of this study.

\subsection{Fatigue Life Improvement by Surface Machining}

Ten testing specimens with reduced surface roughness were prepared by applying the mechanical surface machining process (machining depth: $1 \mathrm{~mm}$ ) to the rough surfaces of the testing specimens. The surface roughness was measured using the same method described earlier (a $45 \mathrm{~mm}$ gauge length and a speed of $0.25 \mathrm{~mm} / \mathrm{s}$ ). The average surface roughness $\left(R_{a}\right)$ was $0.9 \pm 0.5 \mu \mathrm{m}(\mathrm{n}=10)$, and the maximum height roughness $\left(R_{\max }\right)$ was $12.0 \pm 4.3 \mu \mathrm{m}(\mathrm{n}=10)$. It was found that the average roughness decreased approximately 12 times compared to the testing specimens without surface machining.

Likewise, the fatigue test was conducted using the same method as described earlier, and the linear relation between the maximum stress $\left(S_{\max }\right)$ and the fatigue life $\left(N_{f}\right)$ on a log scale was converted to a linear scale:

$S_{\max }=1472.0 \times N_{f}^{-0.034}$

The $R^{2}$ value was 0.874 , which was approximately $11 \%$ higher than that of the testing specimens without surface machining $\left(R^{2}=0.751\right)$, confirming significantly reduced scattering. When the surface roughness was lowered by surface machining, the fatigue limit at $1 \times 10^{6}$ cycles was 920.3 MPa, which was about 10 times higher than the fatigue life (approximately 100,000 cycles) of the testing specimens without surface machining at a similar stress level, which had high surface roughness (Fig. 7). These results are in good agreement with those of previous studies, whereby high surface roughness affects the fatigue life reduction [21-23]. Therefore, it was believed that the improved surface roughness of the center-link chain through mechanical surface machining enhanced the fatigue life and reduced the scattering of the fatigue life in the high-cycle region, thereby improving the reliability of the product. 


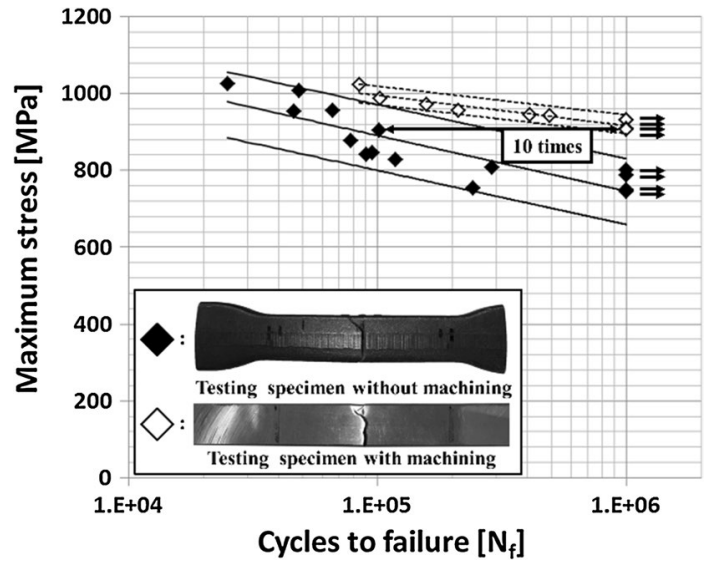

Fig. 7 Comparison of fatigue test results between testing specimens with $(n=10)$ and without $(n=15)$ surface machining that are presented with the upper and lower limits of a $95 \%$ confidence level. The fatigue life of testing specimens with surface machining at the stress of approximately $900 \mathrm{MPa}$ was about 10 times higher than that without surface machining. Fractured specimens are shown in the box at the bottom left of the figure

Table 2 Material properties of SCM440

\begin{tabular}{ll}
\hline Property & Value \\
\hline Young's modulus & $200 \mathrm{GPa}$ \\
Poisson's ratio & 0.3 \\
Tensile strength & 1172.1 \\
Yield strength & 1093.4 \\
\hline
\end{tabular}

\subsection{Fatigue Life Improvement by Shape Design Modification}

\subsubsection{Structural Analysis of the Initial Shape Design}

To determine structural stability improvement due to the shape design modification, finite element analysis was used. First, the structural evaluation of the current product was performed to identify the problem, which was set as the reference value for determining the degree of design improvement. To secure sufficient design stability, a structural analysis (ANSYS V17.2, USA) for the center-link chain was conducted using the worst operating condition that may occur to the center-link chain in the field.

First, three-dimensional (3D) modeling of the center-link chain was performed using CAD software (V5R19, CATIA, France), based on the dimensions specified in the drawing. The 3D-modeled center-link chain was divided into hexahedron elements and 133,785 nodes and 35,156 elements were created. It was confirmed that the maximum skewness was less than 0.85 . The material properties of SCM440 that were used for the structural analysis are shown in Table 2. The loading conditions (tensile and bending loads) were set

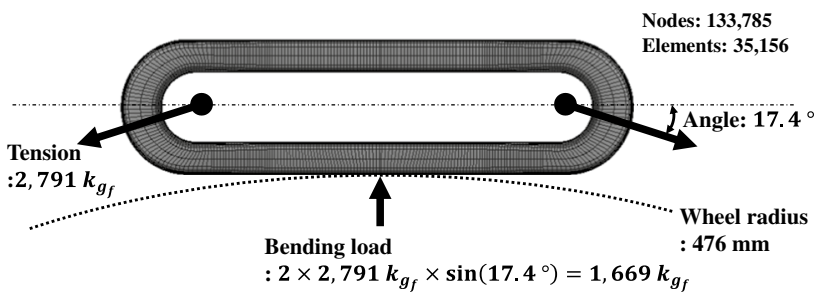

Fig. 8 Finite element model of the center-link chain and the loading conditions for its structural analysis

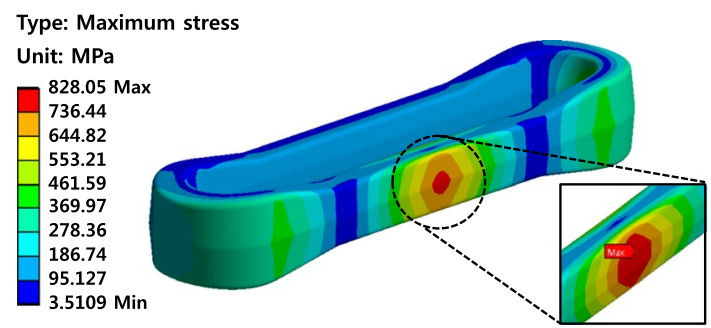

(a) Maximum stress

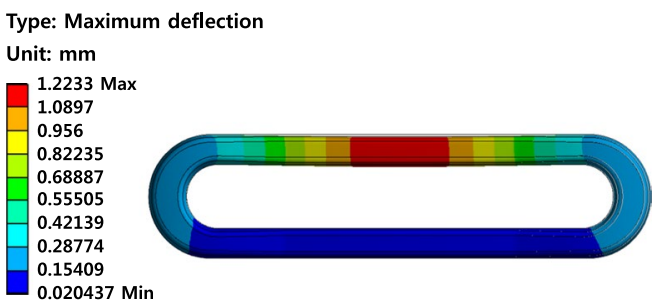

(b) Maximum deflection

Fig. 9 Structural analysis results of the center-link chain under the loading conditions shown in Fig. 8

based on the worst operating conditions of the center-link chain (Fig. 8). While the center-link chain was subject to angular tension, the occurrence of bending at the center of the chain due to the contact with the wheel was simulated.

The structural analysis showed that the maximum stress of $828.1 \mathrm{MPa}$ and maximum deflection of $1.223 \mathrm{~mm}$ occurred at the center of the center-link chain (Fig. 9). The safety factor according to the maximum stress was 1.30 , and the fatigue life was predicted to be 242,651 cycles by the empirical Eq. (1) of the previously calculated S-N curve. The maximum stress was found to be within the scattering range of the S-N curve, suggesting that fatigue failure of the center-link chain could occur unexpectedly under its use conditions. Therefore, it was confirmed that the modification of the center-link chain design was required.

\subsubsection{Modification of the Center-Link Chain Design}

Based on the results of the abovementioned structural analysis, the design was modified to reduce the stress at the center 
of the horizontal part of the center-link chain, where the maximum stress occurred. As the horizontal part is subject to the dominant bending load, the concept of inserting a stiffener vertically to the center point was applied so that deformation due to bending could be alleviated and the bending load could be distributed to the two parallel horizontal parts. As both ends of the stiffener that contact the center-link chain may have the shape of a notch that can cause stress concentration and crack generation, the fillet radius in this contact was selected as a design variable and the design level was determined based on a $3-\mathrm{mm}$ curvature applied to other joints of the conventional product. In addition, as the inclined inner surface of the stiffener facilitates the forging process, this was selected as a design variable. Consequently, for the shape design that considers the prevention of stress concentration at the joints between the stiffener and the center-link chain, a certain volume was provided as a constraint for the design of the stiffener, and the slope angles $\left(82^{\circ}, 86^{\circ}, 90^{\circ}\right)$ of the inner surface of the stiffener, as well as the fillet radii $(1,2$, and $3 \mathrm{~mm})$ of the joints were set as design variables (Fig. 10). To determine the analysis model, nine combinations were created using three levels for each of the two design variables (slope angle and fillet radius) according to the design of experiment, and the structural analysis was conducted for these nine case models (Table 3). The analysis conditions and methods were the same as described in Sect. 4.2.1 above.

Structural analysis showed that the maximum stress occurred near the fillet radius at both ends of the stiffener in all the nine case models (Fig. 11). The maximum stress range was 520-750 MPa and the range of the safety factor calculated based on the yield strength (1073.1 MPa) was approximately 1.4-2.1. The range of the maximum deflection occurring at the center of the center-link chain was approximately $0.423-0.433 \mathrm{~mm}$ (Table 4 ). When the lowest maximum stress that occurred to the Case 9 model was compared with the maximum stress of the conventional model without the stiffener, the maximum stress decreased

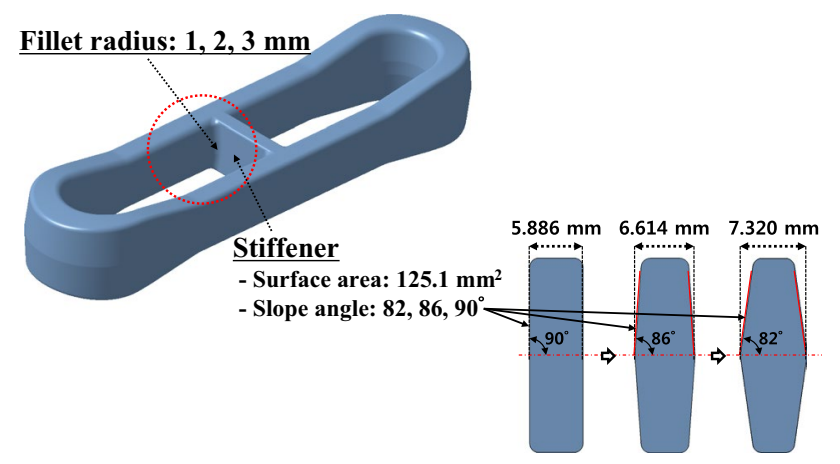

Fig. 10 Change in the stiffener shapes by the design variables (slope angle and fillet radius) of the center-link chain
Table 3 Analysis model cases produced by the design of experiment (DOE)

\begin{tabular}{lll}
\hline Case & \multicolumn{2}{l}{ Design variables } \\
\cline { 2 - 3 } & $\begin{array}{l}\text { Slope } \\
\text { angle }\left({ }^{\circ}\right)\end{array}$ & $\begin{array}{l}\text { Fillet } \\
\text { radius } \\
(\mathrm{mm})\end{array}$ \\
\hline 1 & 82 & 1 \\
2 & 82 & 2 \\
3 & 82 & 3 \\
4 & 86 & 1 \\
5 & 86 & 2 \\
6 & 86 & 3 \\
7 & 90 & 1 \\
8 & 90 & 2 \\
9 & 90 & 3 \\
\hline
\end{tabular}

by approximately 1.6 times from 828.1 to $521.9 \mathrm{MPa}$ and the maximum deflection decreased by approximately 2.9 times from 1.223 to $0.423 \mathrm{~mm}$.

The maximum stress, an objective function for product life improvement, shows the smaller-the-better characteristics. In the case of the smaller-the-better characteristics, the process of obtaining the $\mathrm{S} / \mathrm{N}$ ratio is determined as shown in Eq. (3), and the optimal level of the design variables (slope angle and fillet radius) is the combination of the levels that maximizes the $\mathrm{S} / \mathrm{N}$ ratios. $y_{i}$ represents the maximum stress value shown in Table 4, and $\mathrm{n}$ represents the total number of cases with the same levels for each design variable (slope angle and fillet radius).

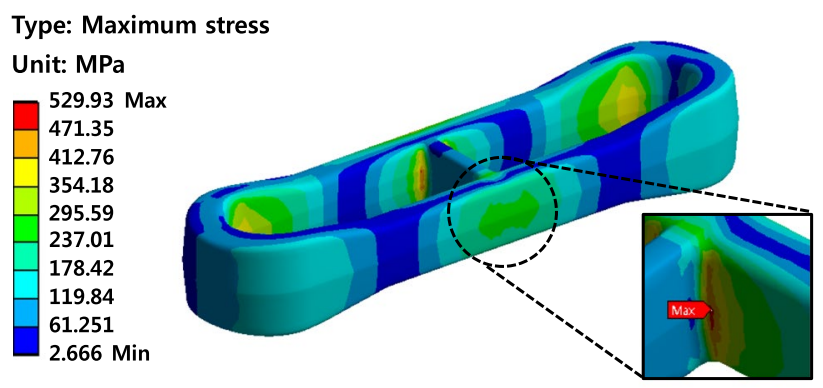

(a) Maximum stress

Type: Maximum deflection

Unit: $\mathrm{mm}$

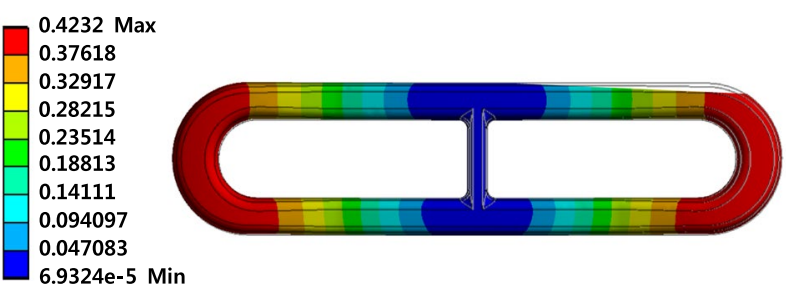

(b) Maximum deflection

Fig. 11 Structural analysis results of Case 6 
Table 4 Maximum stress and maximum deflection in the center-link chain due to tensile and bending loads as per structural analysis

\begin{tabular}{llll}
\hline Case & $\begin{array}{l}\text { Maximum stress } \\
(\mathrm{MPa})\end{array}$ & $\begin{array}{l}\text { Maximum deflec- } \\
\text { tion }(\mathrm{mm})\end{array}$ & Safety factor \\
\hline 1 & 743.8 & 0.433 & 1.44 \\
2 & 577.9 & 0.431 & 1.86 \\
3 & 545.8 & 0.428 & 1.97 \\
4 & 666.8 & 0.428 & 1.61 \\
5 & 573.6 & 0.426 & 1.87 \\
6 & 529.9 & 0.423 & 2.02 \\
7 & 650.8 & 0.428 & 1.65 \\
8 & 542.1 & 0.426 & 1.98 \\
9 & 521.9 & 0.423 & 2.06 \\
\hline
\end{tabular}

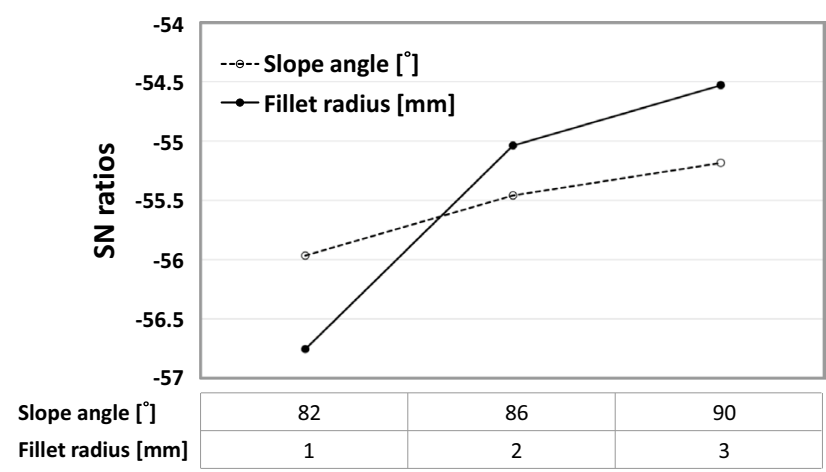

Fig. 12 Main effects plot for the $\mathrm{S} / \mathrm{N}$ ratio of the maximum stress

S/Nratio $=-10 \log _{10}\left[\frac{1}{n} \sum_{i=1}^{n} y_{i}^{2}\right]$

For example, to obtain the $\mathrm{S} / \mathrm{N}$ ratio for a $1 \mathrm{~mm}$ fillet radius, as there are three cases (Case 1, Case 4, and Case 7) where the fillet radius is $1 \mathrm{~mm}$ in the DOE table (Table 4), $\mathrm{n}=3$, $y_{1}=743.8 \mathrm{MPa}, y_{2}=666.9 \mathrm{MPa}$, and $y_{3}=650.8 \mathrm{MPa}$, because $y_{i}$ is the maximum stress value of each case (Case 1, Case 4, and Case 7). Using these values, the $\mathrm{S} / \mathrm{N}$ ratio can be calculated as shown in Eq. (4) below.

$$
\begin{aligned}
\text { S/Nratio } & =-10 \log _{10}\left[\left(y_{1}^{2}+y_{2}^{2}+y_{3}^{2}\right) / 3\right] \\
& =-10 \log _{10}\left[\left(743.8^{2}+666.8^{2}+650.8^{2}\right) / 3\right] \\
& =-56.8
\end{aligned}
$$

As shown in Eqs. (3) and (4) described earlier, the calculation of the $\mathrm{S} / \mathrm{N}$ ratio using design levels of each design variable revealed that a $3-\mathrm{mm}$ fillet radius and a $90^{\circ}$ slope angle were the most stable design levels, as shown in Fig. 12.

When the designing was performed under the constraint that the stiffener has the same volume, joints with uniform width were found to be more effective in distributing the load between the two horizontal parts of the center-link chain. As the fillet radius at the joints between the horizontal parts and the stiffener increased, the stress concentration was reduced. Although the Case 9 model exhibited the lowest maximum stress value of $521.9 \mathrm{MPa}$, the maximum stress of the Case 6 model with inner surface slope showed a small difference of approximately $8 \mathrm{MPa}$. Therefore, considering the easiness of forging, the Case 6 model with a 3-mm fillet radius and an $86^{\circ}$ slope angle was selected as the optimal model (Fig. 11). According to the empirical Eq. (1) of the previous $\mathrm{S}-\mathrm{N}$ curve, the fatigue life of the Case 6 model was predicted to be $109,723,127$ cycles, which was significantly higher than the fatigue life $(242,651$ cycles) of the conventional center-link chain.

\subsection{Selection of a Fatigue Life Improvement Method}

In this study, two methods (Case A: surface machining and Case B: design modification) were examined to improve the fatigue life of the center-link chain (Fig. 13). It was found that the surface roughness reduction through surface machining (Case A) could increase the fatigue life by delaying crack initiation and propagation on the chain surface. Furthermore, it was found that the modification of the shape design of the chain (Case B) could improve the fatigue life by reducing the stress level for the chain. As both improvement methods were judged to be sufficiently effective for the elongation of the fatigue life, it was necessary to review the time and cost required for the actual application of the two methods. Accordingly, the differences between the two methods in the product manufacturing process and cost were analyzed.

For Case A, the current product design and process can be retained and only the surface machining process for the product needs to be added before the product inspection at the end of the process (Fig. 13a). As such, this additional process may result in increased product cost and increased production time. For Case B, it is necessary to add material according to the stiffener installation, and the mold that is used in the current forging and trimming processes needs to be replaced to modify the shape of the product from the conventional process (Fig. 13b). As the mold is a consumable part in the process and must be replaced after a certain amount of use, this method has the advantage of inducing the natural replacement of the mold. The replacement of the mold die, however, carries a considerable cost compared to the unit price of the product. Table 5 shows the factors generating additional product cost according to the two improvement methods.

In Table 5, the added material cost and the added process cost are additional cost factors directly applied to each product. As the replacement cost of the mold die occurs once 


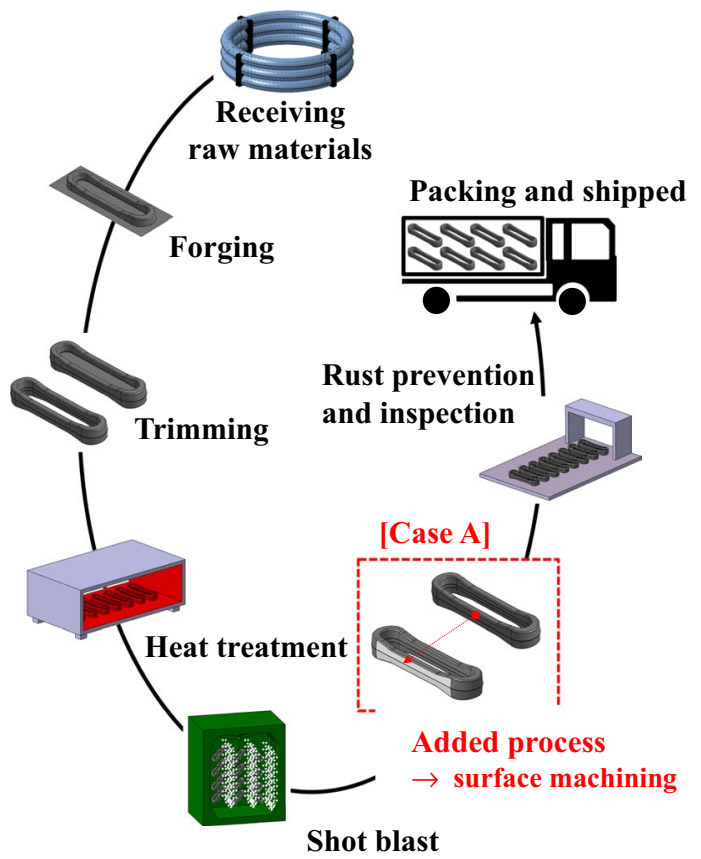

(a) Adding the surface machining process to the process steps (Case A)

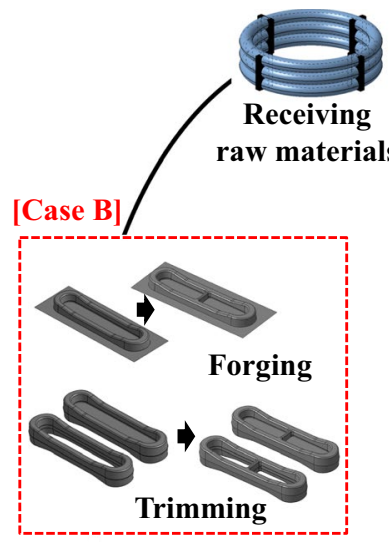

Replacement of mold die

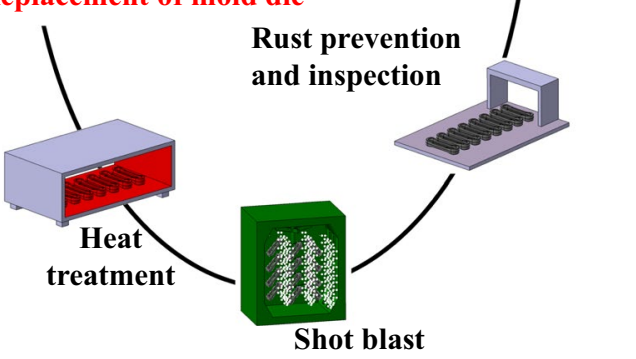

(b) New shape through the mold replacement (Case B)

Fig. 13 Manufacturing process change due to the application of the two fatigue life improvement methods of a center-link chain

during the production of many identical products, $1 / \mathrm{n}$ of the replacement cost of the mold die can be applied to each model if the product is produced in the quantity of $n$ after the mold die replacement. Therefore, the manufacturing costs
Table 5 Factors generating additional product cost according to the center-link chain improvement methods

\begin{tabular}{llll}
\hline & Cost & & \\
\cline { 2 - 4 } & Add material & $\begin{array}{l}\text { Replacement of } \\
\text { mold die }\end{array}$ & $\begin{array}{l}\text { Added } \\
\text { process }\end{array}$ \\
\hline Current design & $\mathrm{X}$ & $\mathrm{X}$ & $\mathrm{X}$ \\
Case A & $\mathrm{X}$ & $\mathrm{X}$ & $\mathrm{O}$ \\
Case B & $\mathrm{O}$ & $\mathrm{O}$ & $\mathrm{X}$ \\
\hline
\end{tabular}

of Case A and Case B required to improve the fatigue life of the center-link chain can be expressed as Eq. (5).

$\begin{aligned} \text { Cost per finished product }= & \text { The current product manufacturing cost } \\ & + \text { Added material cost } \\ & + \text { Added process cost } \\ & + \text { Replacement cost of the mold die/ } \\ & \text { The number of products }\end{aligned}$

As the actual costs of the cost factors shown in Eq. (5) may vary in different countries and in different regions and companies in a country, it is necessary to determine a more economical improvement method by calculating the cost per product according to the local circumstances. Accordingly, in this study, the required cost amount for each cost factor according to a company in South Korea was investigated, and it was confirmed that the same cost factor could lead to different cost amounts depending on the company. However, as the center-link chain is made of SCM440 material, which is relatively inexpensive and widely used in South Korea, the added material led to relatively lower cost increase than the other cost factors (additional process and replacement of the mold die). As the replacement cost of the mold die is the largest item among the three cost factors and is divided by the product output quantity as shown in Eq. (5), the cost added per product is relatively lower if the required product output quantity is large. In other words, the total production cost of Case A was lower than that of Case B if the production output quantity was small.

As the added process cost $=$ added material cost + replacement cost of the mold die/critical production output quantity, the intersection where the total production costs of Case A and Case B are equal can be calculated using Eq. (6) below and indicates the critical production output quantity. It is more economical to apply Case B (the design improvement method) if the production output quantity is larger than the intersection, but if not, the application of Case A (the surface machining method) is more effective.

Critical production output quantity

= Replacement cost of the mold die/ 


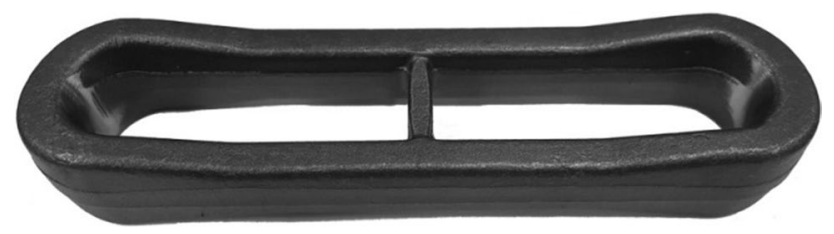

Fig. 14 An actual center-link chain manufactured using the improvement method of Case B

From the practical point of view, the production demand generally exceeds the critical production output quantity in case of the center-link chain, which is the subject of this study. Therefore, Case B was finally selected due to the lower production cost per product than Case A (Fig. 14). Regarding the lead time, moreover, the production output quantity per unit time decreases because of an increase in the lead time per product caused by the added process in Case A. In Case B, however, the same productivity could be maintained because there was no change in the lead time. The center-link chain, which was manufactured with the Case B method, was applied to the actual automobile production process in the filed with no failures reported. Therefore, we believe that the structural stability and reliability as well as the economical practicality has been sufficiently improved by the design improvement of Case B.

\section{Conclusions}

The purpose of this study is to identify the causes of the continuously occurring problem of the failure of center-link chains made of SCM440 material, which are used in the vehicle production field as a major component of a trolley conveyor system, by quantitatively analyzing their failure characteristics under static and dynamic loading conditions and to propose methods for securing their mechanical integrity through changes in their design or manufacturing processes. To analyze the failure phenomenon based on the product itself, testing specimens including the section where the failure of the center-link chain occurred were extracted and a tensile test, hardness test, and fatigue test were conducted using the testing specimens with their original surface property and structural dimension maintained. Owing to the rough surface of the center-link chain manufactured by the forging process, it was found that the elongation was reduced and the deviation of the surface hardness as well as the scattering of the fatigue test result were considerable. Moreover, the rough surface of the center-link chain led to a significantly adverse effect on the fatigue life in the high cycle fatigue. Therefore, the mechanical performance of the actual product may be significantly lower than the predicted performance designed through the test results of the standard testing specimens with the surface machining process.

To improve the fatigue life of the center-link chain, two methods were examined. The first method was to reduce its surface roughness through surface machining, and the second was to improve its shape design. As a result of applying the first method, the fatigue limit value increased by approximately 23\% (746.7-920.3 MPa) and the scattering of the $\mathrm{S}-\mathrm{N}$ curve was improved by approximately $16 \%$ $\left(R^{2}=0.751-0.874\right)$. In the second method, the optimal stiffener shape (design variables: slope angle and fillet radius) that can reduce the stress caused by tensile and bending loads was designed through structural analysis. As a result, the maximum stress (529.9 MPa, Case 6) was reduced by approximately 1.6 times compared to the conventional model (828.1 MPa), leading to a significant increase in the fatigue life from 242,651 cycles to $109,723,127$ cycles. From the practical point of view, the two improvement methods were analyzed regarding process changes and cost factors, when applied to the actual manufacturing process in the field. Considering the critical production quantity of the product, the more practical improvement method was the second method (i.e., to modify the design of the center-link chain shape), because of the lower production cost per product than the first method (i.e., to reduce the surface roughness of the center-link chain through surface machining).

Acknowledgements This research was supported by the National Research Foundation of Korea (NRF) grant funded by the Korea government (MSIP) (No. NRF-2016R1A2B4012561), by Engineering Development Research Center (EDRC) funded by the Ministry of Trade, Industry \& Energy (MOTIE) (No. N0000990), and by "Human Resources Program in Energy Technology" of the Korea Institute of Energy Technology Evaluation and Planning (KETEP) granted financial resource from the Ministry of Trade, Industry \& Energy, Republic of Korea (No. 20164030201230).

Open Access This article is distributed under the terms of the Creative Commons Attribution 4.0 International License (http://creativeco mmons.org/licenses/by/4.0/), which permits unrestricted use, distribution, and reproduction in any medium, provided you give appropriate credit to the original author(s) and the source, provide a link to the Creative Commons license, and indicate if changes were made.

\section{References}

1. Park, Y.-G., Kang, Y.-S., Go, D.-C., \& Sung, D.-Y. (2009). The parametric study effecting on the fatigue life of rail on high speed railway. Journal of the Korean Society for Railway, 12(3), 396-404.

2. Juvinall, R. C., \& Marshek, K. M. (2006). Fundamentals of machine component design. New York: Wiley.

3. Lee, Y.-B., Jeong, J.-S., \& Jo, N.-I. (1996). A study on fatigue behavior considering effects of redistributing tensile residual stress and crack closure in ss330 weldment. Transactions of the Korean Society of Mechanical Engineers A, 20(7), 2234-2245. 
4. Lee, S.-M., Kim, M.-S., Kim, D.-Y., Song, C.-Y., \& Kang, C.-H. (2007). An experimental study on failure mode of space frame's ball joint connection. Journal of the Korean Association for Spatial Structures, 7(6), 61-68.

5. Sonsino, C., \& Kueppers, M. (2001). Multiaxial fatigue of welded joints under constant and variable amplitude loadings. Fatigue and Fracture of Engineering Materials and Structures, 24(5), 309-327.

6. Kueppers, M., \& Sonsino, C. (2003). Critical plane approach for the assessment of the fatigue behaviour of welded aluminium under multiaxial loading. Fatigue and Fracture of Engineering Materials and Structures, 26(6), 507-513.

7. Lee, M.-W., Kim, Y.-J., \& Park, J.-H. (2014). Fatigue assessment of high strength steel welded joints under bending loading. Transactions of the Korean Society of Mechanical Engineers A, 38(10), 1163-1169.

8. Kim, T.-G., Lee, S.-B., \& Lee, H.-C. (2010). A case study on engineering failure analysis of link chain. Safety and Health at Work, 1(1), 43-50.

9. Liu, P., Xing, L., Liu, Y., \& Zheng, J. (2014). Strength analysis and optimal design for main girder of double-trolley overhead traveling crane using finite element method. Journal of Failure Analysis and Prevention, 14(1), 76-86.

10. Kitsunai, Y., Maeda, Y., \& Yoshihisa, E. (1998). Fatigue strength of gusset welded joints under simulated program loading of overhead travelling crane. JSME International Journal Series A Solid Mechanics and Material Engineering, 41(1), 112-120.

11. Davoli, P., Bernasconi, A., Filippini, M., Foletti, S., \& Papadopoulos, I. (2003). Independence of the torsional fatigue limit upon a mean shear stress. International Journal of Fatigue, 25(6), 471-480.

12. Tanaka, T., Arai, J., Nishijima, S., Jowo, M., Shimokawa, T., Tanimoto, T., et al. (1982). Data book on fatigue strength of metallic materials. The Society of Materials Science, 1, 3.

13. Gerber, D. (1998). Evaluation of environmental fatigue effects for a westinghouse nuclear power plant. EPRI report no. TR-110043.

14. Seok, C. S., Park, J. S., Kim, H. I., Lee, Y. M., Cho, W. H., \& Song, W. K. (2005). Evaluation of fatigue characteristic of a real waterworks pipe. In Key engineering materials (pp. 2471-2476), Trans Tech Publ

15. Choi, J.-H., Koo, J.-M., Seok, C.-S., \& Song, W.-K. (2008). Evaluation of fatigue life characteristic of a real waterwork pipe using the probability density function. Transactions of the Korean Society of Mechanical Engineers A, 32(9), 707-712.

16. Choi, J.-H., Koo, J.-M., Seok, C.-S., Kim, J.-H., \& Chang, S.-Y. (2010). Fatigue-characteristic evaluation of a ventilating blade in the air-conditioner. Journal of the Korean Society for Precision Engineering, 27(11), 72-77.

17. Kim, J. W., \& Park, C. Y. (2006). Experimental investigation of the failure behavior of notched wall-thinned pipes. Nuclear Engineering and Design, 236(17), 1838-1846.

18. Yao, W., Xia, K., \& Gu, Y. (1995). On the fatigue notch factor, kf. International Journal of Fatigue, 17(4), 245-251.

19. Pilkey, W. D., \& Pilkey, D. F. (2008). Peterson's stress concentration factors. New York: Wiley.

20. Sung, D.-Y., Park, Y.-G., Go, D.-C., Lee, S.-Y., \& Min, R.-K. (2010). The bending fatigue behavior analysis of rail by bending fatigue test. Journal of the Korean Society for Railway, 13(2), 201-207.

21. Stephens, R. I., Fatemi, A., Stephens, R. R., \& Fuchs, H. O. (2000). Metal fatigue in engineering. New York: Wiley.

22. Rotfe, S., \& Barsom, J. (1977). Fracture and fatigue control in structures. London: Prentice-Hall.

23. Itoga, H., Tokaji, K., Nakajima, M., \& Ko, H.-N. (2003). Effect of surface roughness on step-wise $\mathrm{s}-\mathrm{n}$ characteristics in high strength steel. International Journal of Fatigue, 25(5), 379-385.
24. Srivastava, V., \& Kawada, H. (2001). Fatigue behaviour of alumina-fibre-reinforced epoxy resin composite pipes under tensile and compressive loading conditions. Composites Science and Technology, 61(16), 2393-2403.

25. Ahn, S.-H., Nam, K.-W., Yoo, Y.-S., Ando, K., Ji, S.-H., Ishiwata, M., et al. (2002). Fracture behavior of straight pipe and elbow with local wall thinning. Nuclear Engineering and Design, 211(2), 91-103.

26. Rahman, S., Wilkowski, G., \& Mohan, R. (1997). Low-cycle fatigue crack growth considerations in pipe fracture analyses. Nuclear Engineering and Design, 168(1-3), 105-118.

27. Rahman, M., Hossain, M., \& Rahman, S. (1999). Stress concentration incorporated fatigue analysis of die-marked drill pipes. International Journal of Fatigue, 21(8), 799-811.

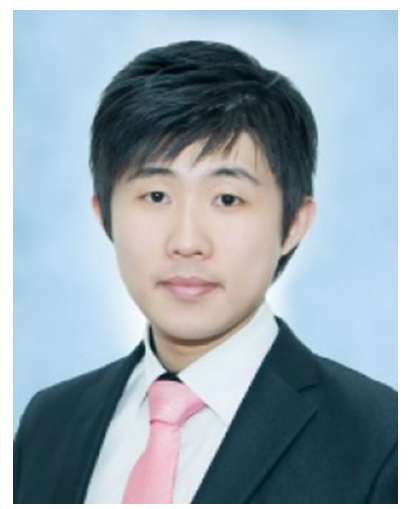

Changwan Han received his B.S. degrees in mechanical \& automotive engineering from Inje University in 2010, and his M.S and $\mathrm{PhD}$ degree from Pusan National University in 2012 and 2019, respectively. His research interests are in the areas of structural design, structural integrity evaluation, and fatigue and failure prediction analysis.

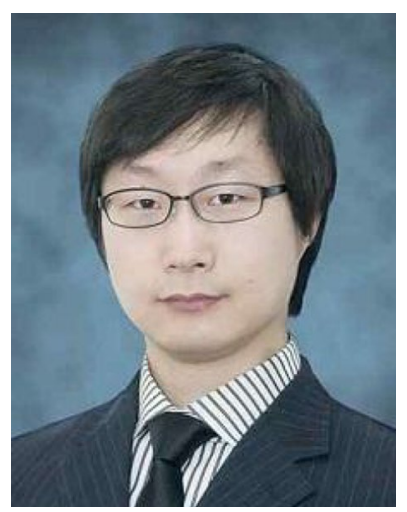

Jae-hoon Lee received his B.S. degrees in 2006, and he completed his Ph.D. course in 2010 at Pusan National University (Mechanical Engineering). $\mathrm{He}$ worked in Samsung Heavy Industries (www.samsungshi .com) as a Senior Researcher of R\&D Department until middle of 2016, and he is currently a Senior Researcher in the Applied Simulation Department of Korea Marine Equipment Research Institute (KOMERI, www.komer i.re.kr). His research interests are in the areas of computational analysis, design optimization, and material analysis.

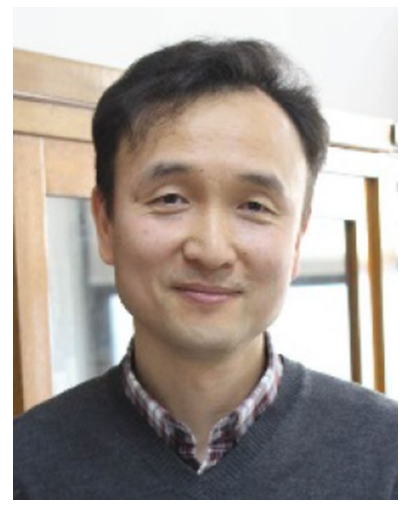

Yoon Suk Choi received his B.S. and M.S. degrees in metallurgical engineering from Pusan National University in 1994 and 1996, respectively, and his $\mathrm{PhD}$ degree from Carnegie Mellon University in 2001. Professor Choi is currently a professor of the School of Materials Science and Engineering, Pusan National University, Korea. His research interests are in the areas of computational materials modeling, metal additive manufacturing and high temperature materials. 


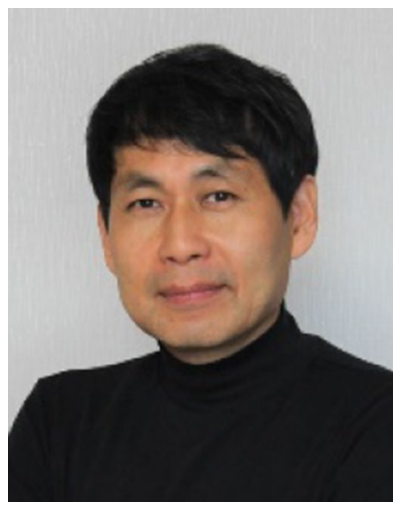

Sang-Hu Park is a Professor in the School of Mechanical Engineering at Pusan National University. He earned his M.S. and $\mathrm{Ph} . \mathrm{D}$. in mechanical engineering at Korea Advanced Institute of Science and Technology (KAIST) in 1996 and 2006, respectively. His research fields are the engineering for metal additive manufacturing, metal forming, and nanofabrication.

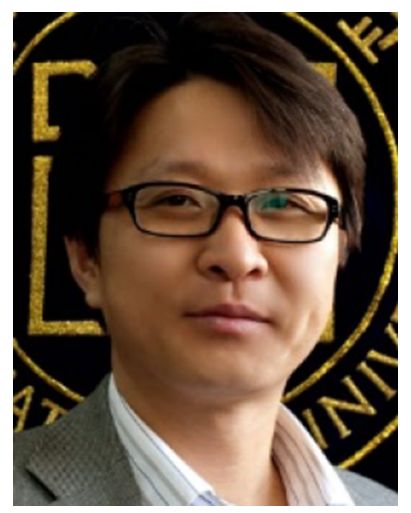

Seonghun Park received his BS and MS degrees in mechanical engineering from KAIST in 1994 and 1996, respectively, and his $\mathrm{PhD}$ degree from Columbia University in 2005. Professor Park is currently a professor of the mechanical engineering department at Pusan National University, Korea. His research interests are in the areas of biomechanics, structural integrity analysis, and material modelling. 